Int. J. Dev. Biol. 51: 351-360 (2007)

doi: $10.1387 /$ ijdb.062258sr

Original Article

\title{
The retinoic acid metabolising gene, CYP26B1, patterns the cartilaginous cranial neural crest in zebrafish
}

\author{
SUSAN REIJNTJES ${ }^{1}$, ADAM RODAWAY ${ }^{1}$ and MALCOLM MADEN ${ }^{*, 2}$ \\ ${ }^{1}$ Randall Division of Cell and Molecular Biophysics and ${ }^{2}$ MRC Centre for Developmental Neurobiology, King's College London, UK
}

\begin{abstract}
We have investigated the function of the retinoic acid metabolising enzyme, CYP26B1, by administering an antisense morpholino oligonucleotide to zebrafish embryos. The result was an alteration in the morphology of the embryo in those regions which express the gene, namely an embryo with a smaller head, correspondingly smaller hindbrain rhombomeres and severely reduced numbers of vagal brachiomotor neurons. Most strikingly, these embryos had defective or absent jaw cartilages implying a role for this enzyme in patterning or migration of the neural crest cells which give rise to this tissue type. In order to determine whether this phenotype resembles that of excess retinoic acid or a deficiency of retinoic acid, we compared the jaw defects following retinoic acid treatment or DEAB treatment, the latter being an inhibitor of retinoic acid synthesis. The effects of the inhibitor rather than excess retinoic acid most closely phenocopied the jaw defects seen with the Cyp26B1 morpholino which suggests that, at least in the zebrafish embryo, the action of CYP26B1 in the neural crest may not be simply to catabolise all-trans-RA.
\end{abstract}

KEY WORDS: Cyp26B1, zebrafish, morpholino, neural crest, retinoic acid, RA, jaw cartilage

\section{Introduction}

Signalling systems in the developing embryo routinely rely on negative feedback control to switch off the inductive signal once it has performed its task on neighbouring cells (Freeman, 2000). Examples of this phenomenon include sprouty/FGF, noggin/ BMP, Dkk/Wnt and in the case of the retinoic acid (RA) signalling pathway, enzymes of the P450 class, the CYP26s, are thought to be responsible for switching off the RA signal. RA is synthesised in cells from its precursor, retinol, by the retinaldehyde dehydrogenases (RALDHs) and it signals to adjacent cells in a paracrine fashion (review, Maden 2002) by entering the nucleus of responding cells to induce a novel pattern of gene expression. This is performed by binding to the retinoic acid receptors (RARs) and the retinoid $X$ receptors (RXRs) which are ligand activated transcription factors (Kastner et al., 1994; Kliewer et al., 1994). There are 3 Cyp26genes, Cyp26A1, Cyp26B1 and Cyp26C1 and each metabolises all-trans-RA into more polar compounds such as 4oxo-RA, 18-OH-RA, 4-OH-RA and 5,6-epoxy-RA (Fujii et al., 1997; White et al., 1997; White et al., 2000). They show dynamic and non-overlapping distributions in the developing mouse, chick, Xenopus and zebrafish embryo (Fujii et al., 1997; de Roos et al., 1999; Swindell et al., 1999; MacLean et al., 2001; Reijntjes et al., 2003; Reijntjes et al., 2004; Tahayato et al., 2003; Emoto et al.,
2005; Zhao et al., 2005; Gu et al., 2005).

Thus within a developing field of cells where RA is required for patterning, one of the RALDHs should be present in signalling cells and one of the CYP26s should be present in cells which function as a sink, thereby generating a gradient of RA between them. Such a system may operate to pattern the posterior hindbrain within the neural plate where Raldh2 is present in the underlying mesenchyme posterior to the level of the first somite and Cyp26C1 is present in the anterior mesenchyme (Reijntjes et al., 2004). There is a gap in between these two expression domains within which a gradient of RA could be generated permitting patterning of the overlying posterior hindbrain. A further model of hindbrain patterning encompasses the differing expression domains of Cyp26A1 and $C 1$ and envisages their function as sequential barriers limiting the anterior spread of RA signalling through the hindbrain rhombomeres (Sirbu etal., 2005). Another region of the embryo where Raldh and Cyp26 domains are closely associated is seen in the developing eye (McCaffery et al., 1999).

To begin to assess the function of the Cyp26genes their action

Abbreviations used in this paper: BMN, brachial motor neuron; DEAB, 4diethylaminobenzaldehyde; $\mathrm{MO}$, morpholino oligonucleotide; RA, retinoic acid; RALDH, retinaldehyde dehydrogenase; RAR, retinoic acid receptor.

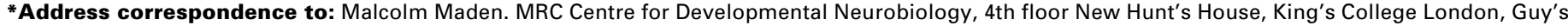
Campus, London Bridge, London SE1 1UL, UK. Fax: +44-207-848-6798. e-mail: malcolm.maden@kcl.ac.uk
} 
can be prevented either by mutating the gene in mouse or by using antisense morpholino oligonucleotides in other vertebrates. The Cyp26A1 knockout phenotype in mouse embryos includes sirenomelia, vertebral defects and hindbrain defects (Abu-Abed et al., 2001; Sakai et al., 2001). Sirenomelia is a feature of excessive RA signalling in the tail bud involving the down-regulation of Wnt3a and brachyury (Sakai et al., 2001) and posterior defects of the hindgut and urogenital system are also a teratological feature of excess RA. Vertebral alterations included missing lumbar, sacral and caudal vertebrae and there was suggestion of anterior to posterior vertebral transformations in the cervical region. Again this defect is suggestive of excessive RA signalling (Kessel \& Gruss, 1991). In the hindbrain there was a decreased size of rhombomeres 2 and 3 , a larger rhombomere 4 and a possible partial transformation of $r 2$ into a r4-like rhombomere. The latter is a feature of RA excess (Marshall et al., 1992). When the level of RA in the mouse embryo is lowered by generating a Raldh2-/+ heterozygote then the posterior truncations in the Cyp26A1 mutant are rescued in the double mutant, Raldh2-/+, Cyp26A1-/(Niederreither et al., 2002). Similarly, in the Xenopus embryo over-expression of Cyp26A1 is able to rescue the effects of exogenous RA treatment (Holleman et al., 1998). These data support the concept that the function of the Cyp26s is to switch off the RA signal.

In zebrafish, the giraffe mutant has a nonsense mutation in the Cyp26A1 gene resulting in a truncated protein and the gir phenotype is mimicked by the injection of antisense mopholinos to Cyp26A1 (Emoto et al., 2005). The phenotype is different to that seen in the mouse knockout. In this zebrafish mutant there is a defective common cardinal vein resulting in a failure of blood cell circulation, a failure of fin buds to develop associated with a loss of Shhand Tbx5.1 expression and a reduction in the size of the rostral hindbrain rhombomeres to compensate for an expansion in the rostral spinal cord territory. These phenotypes are not characteristic of RA excess, instead they are reminiscent of RA deficiency: the vitamin A deficient quail fails to form
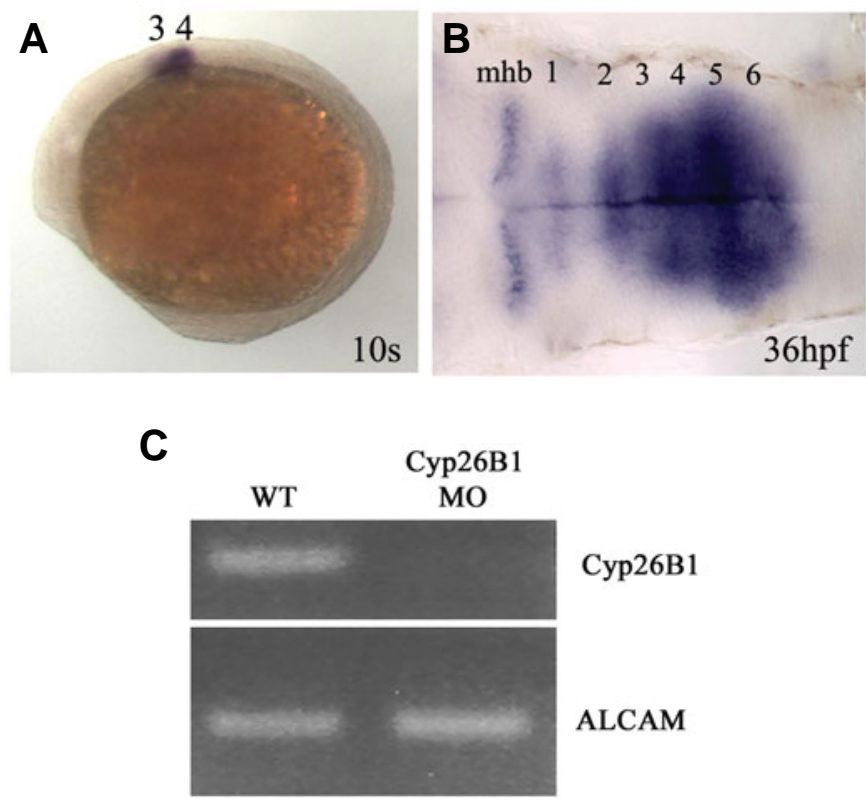

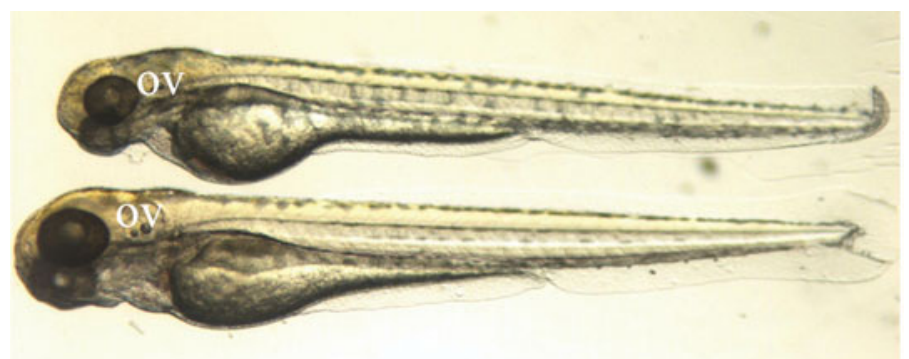

Fig. 2. External appearance of prim-22 (35 hpf) wild-type (lower embryo) and Cyp26B1-splice-MO injected embryos (upper embryo) revealing that the Cyp26B1-splice-MO injected embryos exhibit a decrease in the size of the head region, smaller otic vesicle (ov) and microphthalmia, whereas the trunk seems very similar to normal.

the vitelline vein resulting in a failure of blood cell circulation (Dersch \& Zile, 1995); zebrafish embryos treated with citral, a RA synthesis inhibitor, fail to form fins (Vandersea et al., 1998) as does the Raldh2 mutant zebrafish (Begemann et al., 2001; Grandel et al., 2002); and a reduced hindbrain size is characteristic of the Raldh2 mutant zebrafish and zebrafish and chick embryos treated with a RA synthesis inhibitor (Begemann et al., 2004) or an inhibitor of RA signalling (Dupe \& Lumsden, 2001).

The Cyp26B1 knockout mouse embryo has craniofacial defects including micrognathia which have not yet been described in detail and reduced limbs (Yoshiro et al., 2004). The autopod, zeugopod and stylopod were truncated and fused and in limb bud stages the proximally expressed Meis genes were expanded distally due to the distal expansion of RA signalling. This type of limb abnormality is commonly found after excess RA treatment to mammalian embryos (Kochhar, 1973) as is the distal expansion of Meis genes (Mercarder et al., 2000).

From the above analysis it seems that the Cyp26 knockout mouse and zebrafish phenotypes differ in principle: those in the mouse mimic excess RA administration whereas those in the zebrafish resemble a loss of RA signalling. However, only one Cyp26-/- phenotype has thus far been reported in the zebrafish, that of Cyp26A1, so the available data is rather limited. To this end we describe here the phenotype of a morpholino knockdown of the second Cyp26 gene, Cyp26B1, in zebrafish. We find a phenotype which has some similarities in the hindbrain to the girmutant in that it is smaller, but the major phenotype is a loss of the lower jaw and branchial arch cartilages which have been analysed in detail. We have tried to determine whether this resembles a RA excess or a RA deficiency phenotype by

Fig. 1. (A,B) Cyp26B1 expression at two stages of zebrafish development as examples. (A) Lateral view of a 10 somite stage embryo showing expression in rhombomeres 3 and 4. (B) Flatmount of a 36 hour hindbrain with extensive Cyp26B1 expression in the rhombomeres. Rhombomere numbers are marked; mhb, midbrain/hindbrain border. (C) Semi-quantitative PCR experiments on 25 hpf wild-type and Cyp26B1 splice-MO injected embryos. The upper panel shows successful PCR amplification at 32 cycles of the Cyp26B1 transcript in uninjected control embryos (WT, left side) compared to the Cyp26B1-splice-MO injected embryos (right side) where the morpholino blocked amplification across the exon1/exon2 spliced donor sequence and no product was detected. The lower panel shows no change in expression of the control gene, ALCAM, in both samples. 
treating embryos with inhibitors of RA synthesis or excess RA and the results suggest that they are more similar to a RA deficiency phenotype. The same applies to the hindbrain brachiomotor analysis and as a result we suggest that the Cyp26genes may be behaving differently in the zebrafish than in the mouse embryo.

\section{Results}

The expression pattern of Cyp26B1 has been described before (Zhao et al., 2005) and will not be repeated here. Dynamic expression is seen in various rhombomeres beginning in presumptive $r 4$ and spreading to $1-6$ (Fig. 1A, B), in the ventral diencephalon, at the midbrain/hindbrain border, in the branchial arches, in the eye, pectoral fins and the otic vesicle.

\section{Antisense morpholino injection and RT-PCR}

An antisense oligonucleotide designed to bind to the exon 1/exon 2 splice donor sequence was synthesised and injected into embryos at the $1-8$ cell stage $(0.2-1.25$ hpf) at different concentrations (between $1 \mathrm{mg} / \mathrm{ml}-5$ $\mathrm{mg} / \mathrm{ml}$ ) to determine the optimum. Injection at a concentration of $2.75 \mathrm{mg} / \mathrm{ml}$ (corresponding to $\sim 2 \mathrm{nl} /$ injection) appeared to produce a phenotype when examined morphologically.

Semiquantitative PCR experiments were performed to verify that this Cyp26B1 splice MO was binding to the complementary exon1/exon 2 splice donor sequence and preventing splicing of the Cyp26B1 primary transcript. If endogenous splicing occurred, a product of $246 \mathrm{bp}$ would be observed. If the Cyp26B1-splice-MO successfully bound to the splice donor region then a $246 \mathrm{bp}$ product would not be observed as the resulting product would be in excess of $1.6 \mathrm{~kb}$. Fig. $1 \mathrm{C}$ shows the results from PCR experiments performed using cDNA from RNA extracted from 25hpf embryos. The upper bands show successful PCR amplification at 32 cycles of a $246 \mathrm{bp}$ product in the untreated WT embryos (left side) and confirms that for the injected samples (right side) the Cyp26B1-splice-MO bound to the exon1/exon 2 splice donor sequence and blocked PCR amplification across this sequence. The lower bands show no change in the expression of the control gene, activated leukocyte cell adhesion molecule (ALCAM), in the Cyp26B1splice-MO injected embryos. These PCR experiments were repeated 3 times using 3 separate batches of cDNA synthesized from RNA extracted from $25 \mathrm{hpf}$ wild type control and Cyp26B1 splice MO injected embryos.

\section{External examination of wild-type and Cyp26B1- splice-MO injected embryos}

Fig. 2 shows a wild-type embryo (lower embryo) and a Cyp26B1-splice-MO injected embryo (upper embryo) at matched somite stages. The Cyp26B1-splice-MO injected embryos exhibit an overall decrease in size of the head region, smaller otic vesicle and microphthalmia, but from the otic vesicle posterior there was no difference in the length of the embryos. This phenotype was observed in $77 \%$ of embryos examined (83 out of 107 embryos). Cardiac oedema was exhibited in a small number of embryos $(5 \%)$.

\section{Hindbrain gene expression domains and BMN organisation}

Because of the smaller size of the head we determined whether there was a hindbrain phenotype, for example missing rhombomeres. In fact all the rhombomeres were present, but they were reduced in size by about $40 \%$ in terms of dimensions and cell number. Rhombomere 4, for example, as marked by Hoxb1A expression was smaller (Fig. 3A, B), the distance from the midbrain/hindbrain border was shorter (Fig. 3C, D) and the Krox-20stripes in $\mathrm{r} 3$ and $r 5$ were narrower (Fig. 3E, F). The only
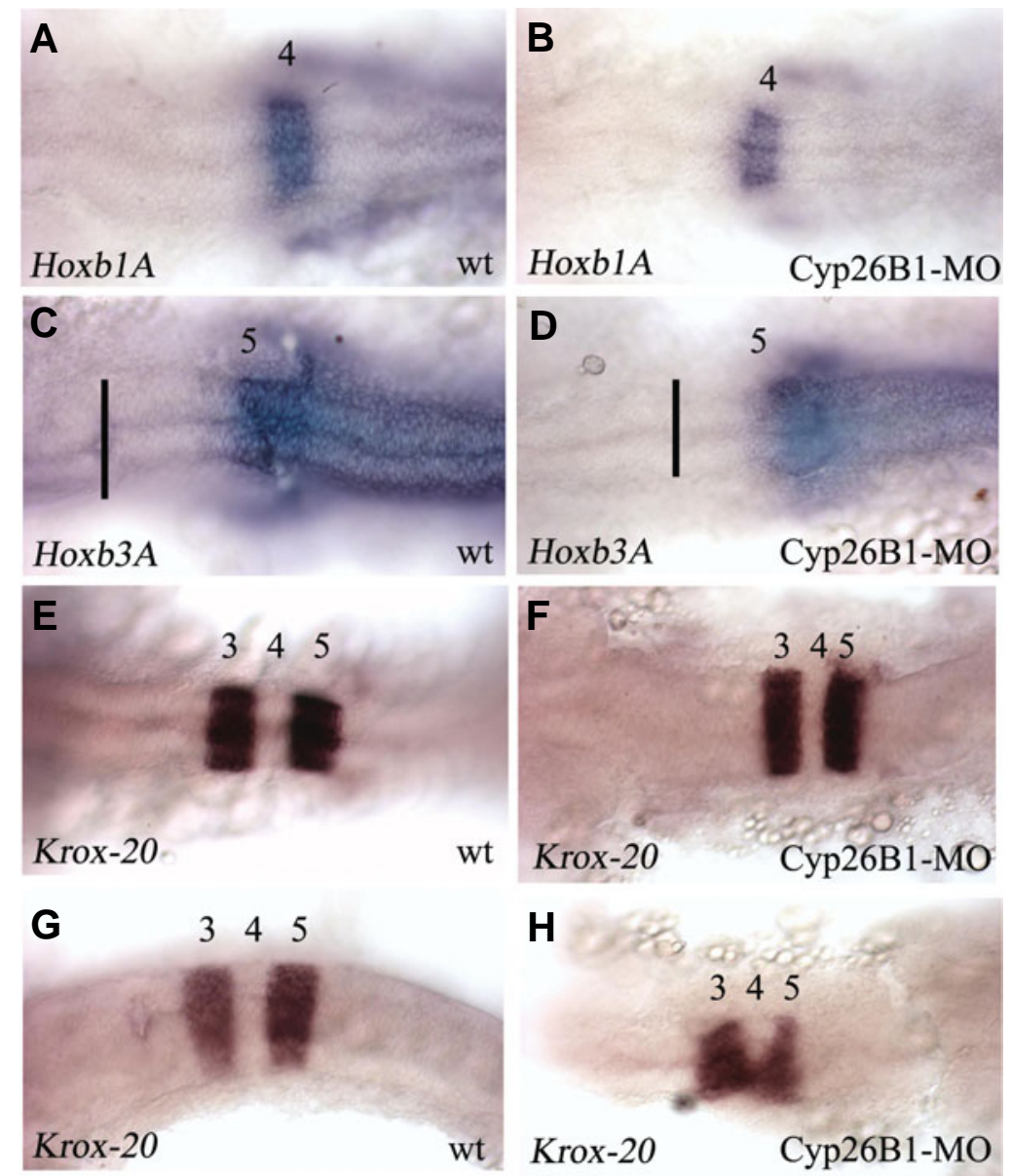

Fig. 3. Expression of three hindbrain genes in control and morpholino injected embryos. (A) Control Hoxb1A expression at the 18 somite stage in rhombomere 4. (B) Morpholino injected embryo at the 18 somite stage showing normal Hoxb1A expression, but $\mathrm{r} 4$ is reduced in size. (C) Control Hoxb3A expression at the 18 somite stage showing the distance between the midbrain/hindbrain border (black line) and the expression from r5 caudally. (D) Morpholino injected embryo at the 18 somite stage showing normal Hoxb3A expression, but the distance from the midbrain/hindbrain border (black line) is reduced. (E) Krox-20 expression in $\mathrm{r} 3$ and $\mathrm{r} 5$ in a normal 10 somite stage embryo. (F) Krox-20 expression in a 10 somite stage morpholino injected embryo showing the reduced size of $r 3$ and $r 5$. (G) Krox-20 expression in $r 3$ and $r 5$ in a normal 18 somite stage embryo. (H) Krox-20 expression in a morpholino injected 18 somite stage embryo showing ectopic expression into the gap between $r 3$ and $r 5$. 

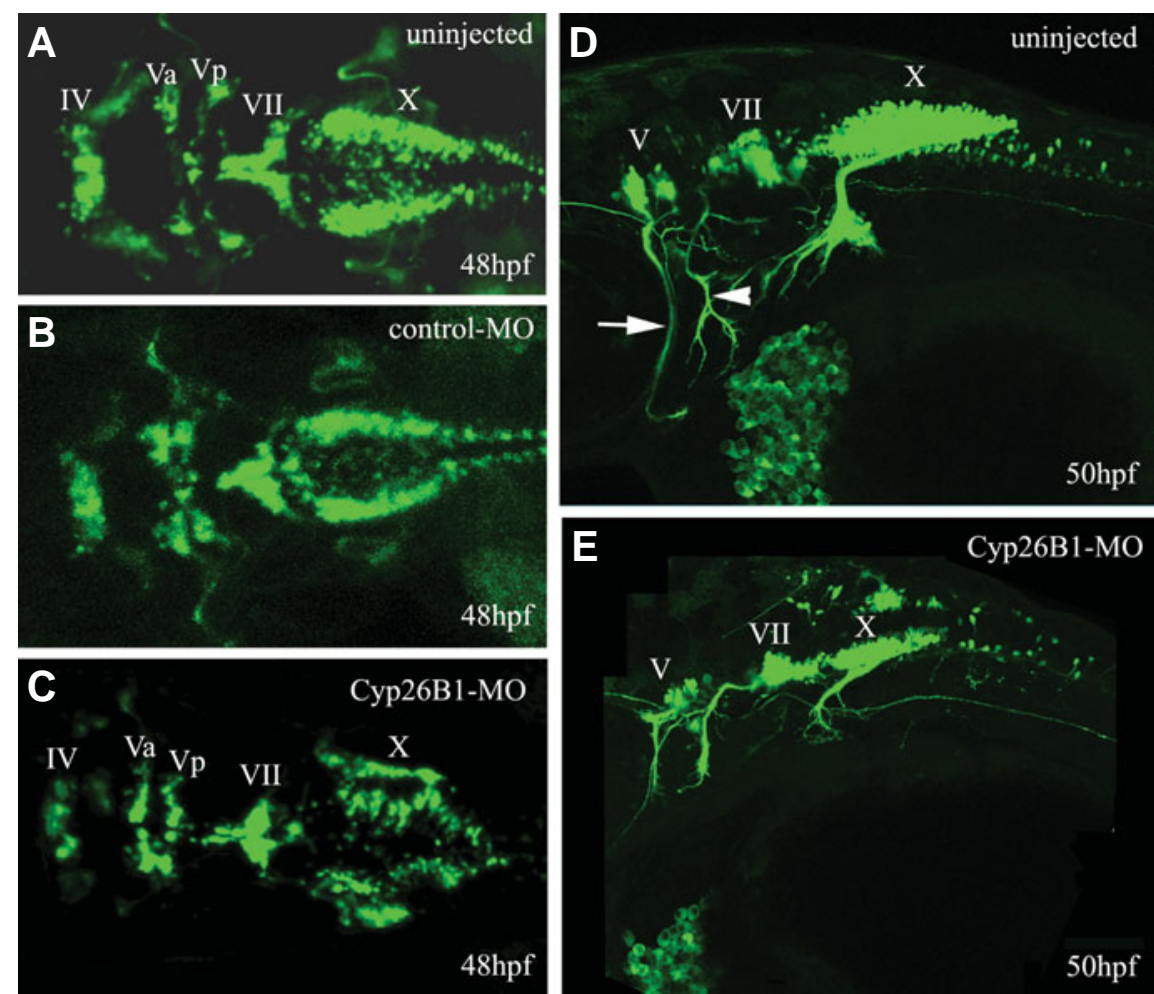

Fig. 4. Confocal micrographs of the brachiomotor neuron (BMN) pattern in the hindbrains of control and morpholino injected embryos examined using the Islet-1-GFP transgenic zebrafish. (A-C) Dorsal views of the hindbrain, rostral is to the left. (D,E) Lateral view of the hindbrain; rostral is to the left. (A) Live, uninjected control embryo at $48 \mathrm{hpf}$ showing neurons of the trochlear nucleus (IV), trigeminal nucleus (Va and Vp), facial nucleus (VII) and the vagal nucleus $(n X)$ which correspond to rhombomeric segmentation. (B) A hindbrain of a control-MO injected embryo at $48 \mathrm{hpf}$. The Cyp26B1-splice sequence was scrambled to ensure that any defects exhibited in the hindbrain of the Cyp26B1-splice-MO injected embryos were not due to toxicity problems associated with MO injection. The same organisation of nucleias seen in (A) is apparent here. (C) Hindbrain of a Cyp26B1-splice-MO injected embryos at 48 hpf. There is a reduced number of BMNs throughout the smaller hindbrain, but particularly affected is the vagus $(X)$ which shows a strongly reduced number of neurons. (D) Lateral view of an uninjected control embryo indicating peripherally extending axons from the trigeminal (V) nucleus (white arrow), the facial (VII) nucleus (white arrowhead) and the vagus (X). (E) Lateral view of a Cyp26B1-splice-MO injected embryo showing much smaller nuclei and far less extensive projections of the axons from those nuclei. other abnormality seen in these gene expression patterns was the very occasional loss of the integrity of $r 4$ in that at later stages Krox-20expression seemed to be expanding into this rhombomere (Fig. 3H).

To examine the brachial motor neuron (BMN) organisation the Cyp26B1 MO was injected into embryos carrying the Islet-1-GFP transgene. This transgene is expressed in postmitotic motor neurons early in their development (Higashijima et al., 2000). Injected embryos were stage matched with uninjected controls and the motor neurons examined by confocal microscopy. At 48hpf a control embryo showed a typical organisation of brachimotor neurons with the trochlear nucleus (IV) being the most rostral group, two trigeminal groups (Va and Vp), a characteristic L-shaped facial nucleus (VII) and an extensive cluster of neurons making up the vagus (X) (Fig. 4A). A lateral view of an uninjected control embryo (Fig. 4D) at 50hpf shows peripherally extending axons from the trigeminal (white arrow), facial (white arrowhead) and a large vagus nerve.

A similar organisation of brachiomotor neurons was seen in a control morpholino injected embryo (Fig. 4B). This control was performed to ensure that any motor neuron defects observed in the Cyp26B1-splice-MO injected embryos were not due to toxicity problems associated with MO injection. A morpholino was synthesized that had the splice oligonucleotide sequence scrambled and this was injected into embryos at the same stage and concentration $(2.75 \mathrm{mg} / \mathrm{ml})$ as the Cyp26B1-splice-MO. Confocal analysis confirmed that the injected control embryos exhibited no motor neuron defects compared to uninjected control embryos (Figs. 4A,B). In contrast, the Cyp26B1-splice-MO injected embryos exhibited a decreased overall hindbrain size as expected from the previous in situanalysis (Fig. 3). The trochlear, trigeminal and facial nuclei were clearly present in their characteristic locations and with their characteristic shapes, but the most affected structure was the vagus (Fig. 4C) which showed a striking reduction in neuronal number and disorganisation. A lateral view of a 50hpf Cyp26B1-splice-MO injected embryo (Fig. 4 ) revealed that the axonal projections from the trigeminal $(n V)$, facial (nVII) and vagal ( $\mathrm{nX}$ ) neurons were present in their appropriate locations, but their extension and progress was strongly retarded in that they had not innervated the pharyngeal arches. This may suggest an underlying defect in the pharyngeal arches.

\section{DIx2 analysis}

In order to begin an analysis of a potential pharyngeal arch problem in these Cyp26B1-splice-MO injected embryos we examined the expression of the $D / x 2$ gene which is expressed in the migrating neural crest cells populating the visceral arches in zebrafish and mouse (Bulfone et al., 1993; Akimenko et al., 1994) and perturbing this homeobox gene results in cranial cartilaginous defects (Graham, 2002). Treating zebrafish embryos with excess exogenous RA causes a down-regulation of $D / \times 2$ gene expression resulting in the absence or abnormal development of cranial neural crest-derived cartilaginous elements (Ellies et al., 1997). Therefore, in situ hybridisation with a $D / x 2$ riboprobe was carried out on 2-day old wild-type and Cyp26B1-splice-MO injected embryos to determine whether knocking down the function of CYP26B1 affected D/X2 expression in migrating crest. In control wild-type embryos expression of $D / x 2$ was seen in the mandibular pharyngeal arch, the hyoid pharyngeal arch, the second branchial gill arch, the otic vesicle and the pectoral fin (Fig. $5 A)$. D/x2 expression was reduced within these domains in Cyp26B1-splice-MO injected embryos (Fig. 5B). A ventral view of a wild-type 2 day embryo shows $D / x 2$ gene expression in the neural crest cells that will form the components of the lower jaw 
(Fig. 5C) whereas in the Cyp26B1-splice-MO injected embryos, weaker $D / x 2$ expression is observed in this domain (Fig. 5D).

\section{Defective craniofacial cartilage development in the Cyp26B1- splice-MO injected embryos}

The reduction in $D / x 2$ expression and failure of the branchiomotor neurons to extend into the branchial arches suggested the possibility of an arch defect in the absence of Cyp26B1 expression. To investigate this we cut serial transverse plastic sections of the heads of $35 \mathrm{hpf}$ embryos. A section through a normal embryo in Fig. 5E reveals the diencephalon, the layers of the developing retina and lens and the neural crest derived mesenchyme that has formed the craniofacial cartilages such as the trabeculae cranii of the upper jaw and the palatoquadrate and Meckel's cartilage of the lower jaw. Sections though the Cyp26B1splice-MO revealed a complete absence of cartilaginous jaw structures with an almost absent mouth (Fig. 5F). The eyes were smaller in the Cyp26B1-splice-MO injected embryos, they were less well differentiated and appeared to have moved ventrally, probably due to the loss of the neural crest derived mesenchyme.

Cartilage staining with Victoria blue was undertaken in 5-day old control and Cyp26B1 splice-MO injected embryos to more precisely assess the cartilaginous defects. The wild-type viscerocranium is shown in Fig. 6A. Meckel's cartilage and the palatoquadrate are derived from the mandibular pharyngeal arch neural crest, the ceratohyals and the hyosymplectics are derived from the hyoid and posteriorly lie five gill associated ceratobranchial (cb) cartilages, derived from neural crest migrating into pharyangeal arches 3-7. Neural crest migrating into the maxillary process gives rise to the cartilage components of the neurocranium, or upper jaw (Fig. 6B), the trabeculae cranii, ethmoid plate and the posterior parachordal.

Injection of the control $\mathrm{MO}$ resulted in no cartilaginous defects (Fig. 6C; 39/39 injected embryos) and the resulting embryos were structurally normal, as they were in terms of their BMN organisation (Fig.

Fig. 5. (A-D) DIx2 expression in wild-type and Cyp26B1splice-MO injected embryos. (A) Lateral view of a wildtype 48 hpf embryo showing Dlx2 expression in the $1^{\text {st }}$ mandibular arch $(m)$, the $2^{\text {nd }}$ hyoid arch ( $h$ ) and branchial gill arch 2 (2), the otic vesicle (ov) and pectoral fins (pf). (B) Ventral view of a 48 hpf wild-type embryo showing DIx2 expression in the neural crest cells that will form cartilaginous components of the lower jaw (lj). (C) Lateral view of a Cyp26B1 splice MO injected 48 hpf embryo showing strong reduction of Dlx2 expression in all the domains except the pectoral fin. (D) Ventral view of a Cyp26B1 splice MO injected 48 hpf embryo showing a reduction of Dlx2 expression in the neural crest. (E,F) Transverse plastic haematoxylin and eosin stained sections of the heads of 35 hpf embryos. (E) An uninjected control embryo showing the normal structure of the head and cartilaginous components of the jaw. Tc, trabeculae cranii of the upper jaw; pq, palatoquadrate; mc, Meckel's cartilage. (F) ACyp26B1-splice-MO injected embryo. There is a huge reduction in the size of the head although the brain and eyes are still present. All of the jaw cartilage is absent and there is virtually no mouth (arrow).
4B). In the Cyp26B1-splice-MO injected embryos, on the other hand, the jaw cartilages were severely affected and exhibited a wide range of abnormalities in the upper and/or lower jaw cartilaginous apparatus and/or the gill associated cartilages. An example of the least severely affected embryo is shown in Fig. 6D where only the ceratohyals were affected and instead of projecting rostrally to form the lower jaw they projected medially (Fig.6D, ch). The ceratohyals, derived from the second arch, were always affected in every embryo and thus seemed to be the most sensitive structure to the loss of Cyp26B1 expression. The next grade of effect was one in which both the second and first arch derivates were abnormal (Fig. 6E). The ceratohyals projected medio-caudally (Fig. 6E, ch) and the palatoquadrates and Meckel's cartilage were misshapen, the latter forming a more circular structure rather than the characteristic arc and failed to fuse at the midline (Fig. 6E, white arrow). In addition, some of the posterior ceratobranchials, basibranchials and hypobranchials were absent (Fig. 6E, red arrow). In the next most severely affected examples the palatoquadrate cartilages were completely absent (Fig. 6F, white arrow) while Meckel's cartilage was still present and the ceratohyals had their characteristically altered direction of development (Fig. 6F, ch). Most of the ceratobranchials, basibranchials and hypobranchials were absent and this embryo also exhibited cardiac oedema (Fig. 6F, red arrow). An equally affected class of embryo is shown in Fig. 6G where both the
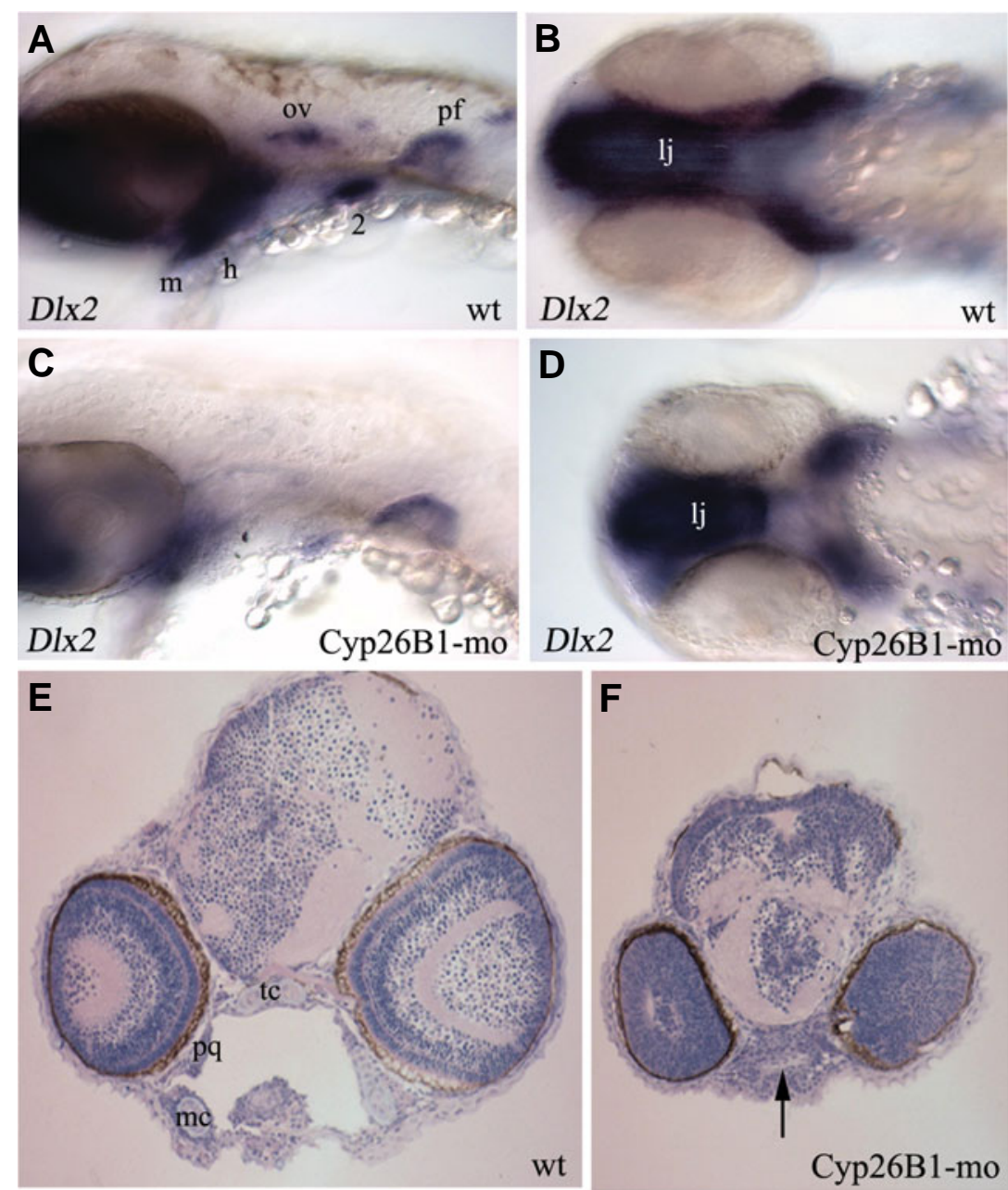
Meckel's and the palatoquadrate cartilages have failed to develop, the certohyals project caudally instead of rostrally and the ceratobranchials on the left side have failed to develop (Fig. 6G, white bracket) which could reflect mosaicism of the splice morpholino. In the most severely affected cases there were no jaw cartilages of the neurocranium or viscerocranium present at all (Fig. $6 \mathrm{H}$ ) and the eyes moved closer together as shown in the section in Fig. 5F.

In all Cyp26B1-splice-MO injected embryos, pectoral fin development appeared normal and the lens always developed despite some embryos exhibiting microphthalmia. A summary of all the cartilaginous jaw/gill structure phenotypes in the Cyp26B1-spliceMO injected embryos is presented in Table 1.

\section{DEAB and RA administration}

It is clear that injection of the splice MO causes abnormal differentiation in the neural crest derived cartilaginous components of the upper and lower jaw and branchial gill arches 1-5 causing them to be missing or malformed. In an attempt to establish whether the phenotypes observed when preventing translation of $C y p 26 B 1$ might be due to a lack of biologically active CYP26B1 generated RA products, or a failure of CYP26B1 to get rid of the RA signal, thereby exposing embryos to excess RA, embryos were treated with an inhibitor of RA synthesis, 4diethylaminobenzaldehyde (DEAB), or all-trans-RA. Victoria blue preparations were made of 5-day old wild-type embryos treated for 19 hours from $50 \%$ epiboly stage (5.3hpf) with separate treatments of $50 \mu \mathrm{M}$ DEAB, $10 \mu \mathrm{M}$ DEAB, $1 \times 10^{-8} \mathrm{M}$ all trans RA and $3 \times 10^{-9} \mathrm{M}$ all trans RA. As controls, siblings were treated with equivalent concentrations of DMSO, which had no effect.

Treatment with $50 \mu \mathrm{M}$ DEAB resulted in embryos exhibiting many of the cartilaginous phenotypes observed in the Cyp26B1splice-MO injected embryos. The most striking effect was the near complete absence of the neural crest-derived ceratobranchials, basibranchials and hypobranchials from the branchial gill arches $1-5$ in 13 out of 14 DEAB treated embryos (Fig. 6I). In 8 out of 14

TABLE 1

\section{ANALYSIS OF CARTILAGINOUS JAW OR GILL MUTANTS AFTER CYP26B1 MO INJECTION}

\begin{tabular}{lc} 
Phenotypic class & No. of embryos \\
\hline No phenotype observed & 9 \\
Components of the neurocranium missing or malformed & 11 \\
Components of mandibular arch missing or malformed & 1 \\
Components of hyoid arch missing or malformed & 6 \\
Components of mandibular and hyoid arch missing or malformed & 16 \\
Components of posterior (gill) arches missing or malformed & 31 \\
Components of all pharyngeal arches missing or malformed & 9 \\
& (total no. examined 41)
\end{tabular}

79\% of Cyp26B1-splice-MO injected embryos exhibited a phenotype

TABLE 2

CARTILAGINOUS JAW OR GILL PHENOTYPES IN THE CYP26B1MORPHOLINO, RA AND DEAB TREATED EMBRYOS

\begin{tabular}{lccc} 
Phenotypic class & Cyp26B1-MO & DEAB & RA \\
\hline Neurocranium absent or malformed & $34 \%$ & $18 \%$ & $88 \%$ \\
$1^{\text {st }}$ and $2^{\text {nd }}$ arches absent or malformed & $50 \%$ & $59 \%$ & $83.5 \%$ \\
Gill arches absent or malformed & $96 \%$ & $96 \%$ & $23 \%$ \\
\hline
\end{tabular}

DEAB treated embryos, the neural crest-derived cartilaginous derivatives of the first arch (Meckel's and the palatoquadrate cartilages) showed a characteristic absence of the palatoquadrates (arrow in Fig. 6J) and a small Meckel's cartilage which did not connect to anything and the characteristic second arch abnormality of medially projecting ceratohyals (Fig. $6 \mathrm{~J}, \mathrm{ch}$ ). The similarity between this DEAB treated embryo and the Cyp26B1 morpholino injected embryo in Fig. $6 \mathrm{~F}$ is very striking. Components of the second arch (interhyals, ceratohyals and basibranchials) were absent or malformed in 7 out of 14 treated embryos and, as described above, the ceratohyals projected medially instead of rostrally. The neurocranium, although present in all DEAB treated embryos, was misshapen in 3 out of 14 cases. Many of the first and second arch defects present in the morpholino treated embryos were phenocopied by DEAB treatment. For example Fig. 6I shows an embryo with medially projecting ceratohyals with a relatively normal, albeit smaller, Meckel's cartilage and palatoquadrates which is very similar to the mopholino embryo in Fig. 6D.

Very similar results were obtained with $10 \mu \mathrm{m}$ DEAB treated embryos such that the results were indistinguishable. Other abnormalities observed in the DEAB treated embryos at both concentrations were absence of pectoral fins, microphthalmia, cardiac oedema and a reduction in head size.

Treatment with $1 \times 10^{-8} \mathrm{M}$ all-trans-RA resulted in embryos with a different type of jaw cartilage defect to that seen with DEAB or Cyp26B1 morpholinos. In 24 out of 24 embryos the cartilaginous derivatives of the first arch (Meckel's cartilage and the palatoquadrate) and the neurocranium were malformed or absent whereas the five gill associated ceratobranchial (cb) cartilages were, in general, well formed (Fig. 6K). This figure shows that as a result of the loss of the neurocranium and the lower jaw the anterior head appeared truncated with the eyes having lost a lot of pigmentation lost their lenses and having come closer together ventrally. The second arch-derived bilateral components of the ceratohyal cartilages were malformed or absent in all 24 out of 24 all-trans-RA treated embryos. They did not extend rostrally and appeared thicker, which we interpret as a duplication (Fig. 6K, L ch). Components of the five gill associated branchial arch cartilaginous structures were absent or malformed in only a minority of all-trans-RA treated embryos. Other defects observed in the RA treated embryos included duplication of the pectoral fins and cardiac oedema in $100 \%$ of cases and microphthalmia or anophthalmia with an absence of the lens.

Treatment with $3 \times 10^{-9} \mathrm{M}$ RA resulted in embryos exhibiting many of the phenotypes observed after treatment with $1 \times 10^{-8} \mathrm{M}$ all-trans-RA, but with less than $100 \%$ frequency. The cartilaginous components of the first arch were absent or poorly formed in 24 out of 28 embryos (Fig. 6L) and the neurocranial cartilages were absent or malformed in 22 out of 28 embryos. The second arch-derived ceratohyals were formed and again appeared thickened as if duplicated (as shown in Fig. 6L) in 15 out of 28 all-transRA treated embryos. Components of the five gill associated branchial arch cartilaginous structures were generally well formed (as shown in Fig. 6K, L) and only reduced or absent in 5 out of 28 embryos. Other defects which appeared were the same as at the higher concentration of $\mathrm{RA}$, but with a reduced frequency including cardiac oedema, duplication of the pectoral fins and only 2 out 28 embryos failed to form a lens. 

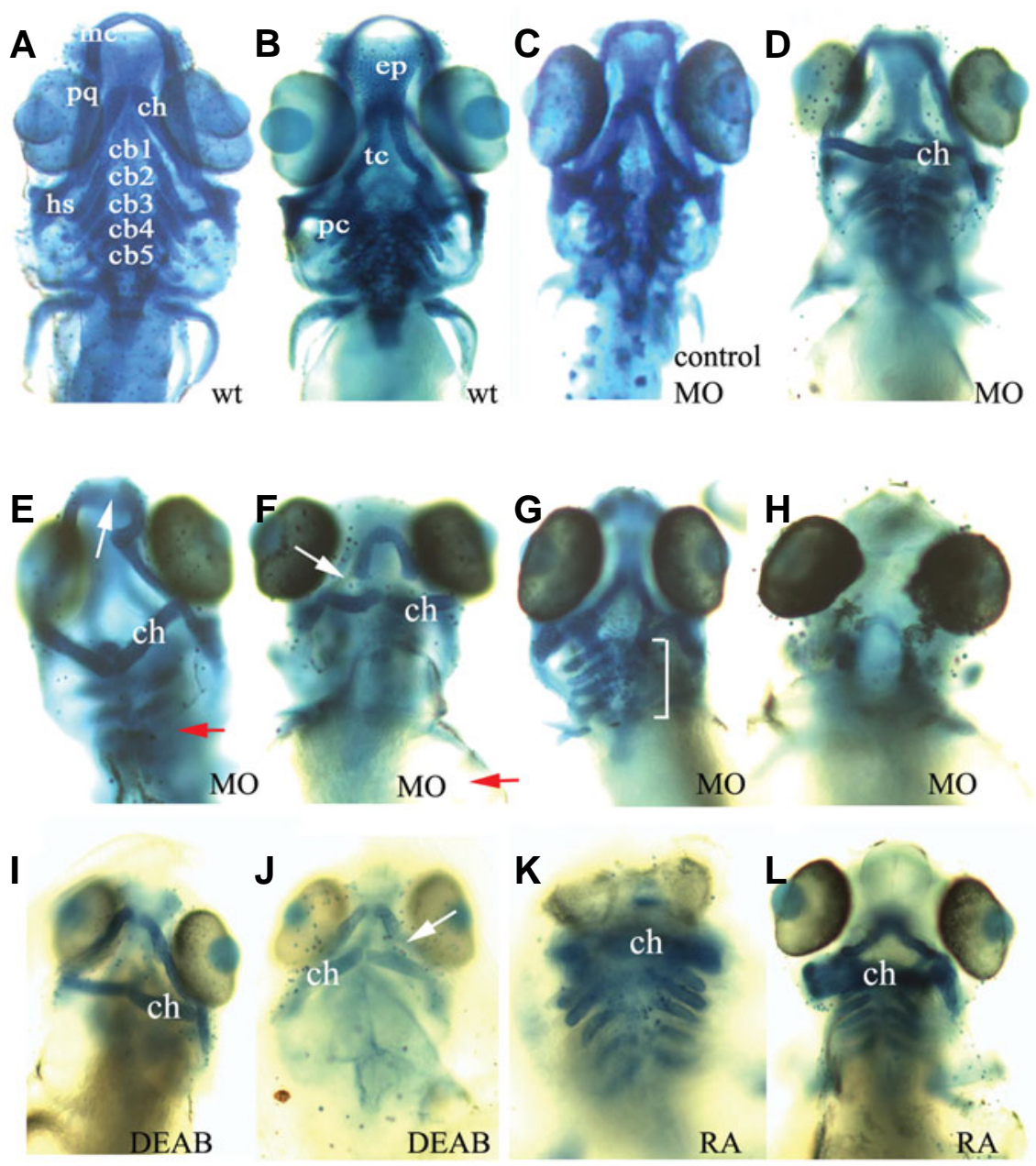

Fig. 6. Ventral views of Victoria blue stained 5-day old embryos to reveal the cartilage. (A,B) Wildtype; (C) control MO injected; (D-H) Cyp26B1-spliceMO injected; (I,J) DEAB treated; $(\mathbf{K}, \mathbf{L})$ all-trans-RA treated. (A) Wild-type embryo. Meckel's cartilage (mc) and the palatoquadrate (pq) are formed from the first (mandibular) pharyngeal arch mesenchyme. The supporting ceratohyals (ch) and the hyosympletics (hs) are formed from the second (hyoid) pharyngeal arch mesenchyme. The five gill associated ceratobranchials (cb1-cb5) are formed from the thirdseventh pharyngeal arch mesenchyme. (B) Wild-type embryo showing the neurocranium. The trabeculae cranii (tc), the ethmoid plate (ep) and parachordal cartilage $(p c)$ are formed from neural crest migrating into the frontal nasal process (maxillary). (C) Control MO injected embryo confirming that cartilaginous defects were not due to the effects of MO toxicity. (D) The mildest Cyp26B1-splice-MO injected phenotype displaying a normal Meckel's cartilage and palatoquadrates, but with ceratohyals (ch) which project medially instead of rostrally. (E) A more abnormal morpholino phenotype in which Meckel's cartilage is abnormally shaped forming a more circular structure that has failed to meet in the midline (white arrow), the second arch derived ceratohyals (ch) are curving medially and some of the gill associated ceratobranchials are absent (red arrow). (F) A more abnormal morpholino phenotype where Meckel's cartilage is present, but the palatoquadrates are absent (white arrow), the certaohyals (ch) project medially and all of the gill associated ceratobranchials are absent. This embryo also exhibits cardiac oedema (red arrow). (G) A severe morpholino phenotype with completely absent first arch components (Meckel's cartilage and palatoquadrates), caudally projecting ceratohyals and the ceratobranchails are missing on one side only (white bracket). The upper jaw of the neurocranium is normal. (H) The most severe morpholino phenotype with a completely absent jaw apparatus. (I) DEAB treatment causes a strikingly similar phenotype to the morpholino embryo in (D) with medially projecting ceratohyals (ch). (J) DEAB treatment has caused a similar phenotype to the morpholino embryo in (F) with missing palatoquadrates (white arrow) and medially projecting ceratohyals (ch). (K) RA treatment of this embryo has caused an anterior truncation with loss of lenses and pigmentation in the eyes which have moved closed together, missing neurocranium and upper jaw, missing first arch cartilages, thickened certatohyals (ch) which look duplicated and fully present ceratobranchials. (L) A lower concentration of RA allowed this embryo to develop the upper jaw, but not the first arch components of the lower jaw and, again, the certatohyals (ch) look duplicated.

A summary of the cartilaginous defects observed in the Cyp26B1 morpholino embryos in comparison to the RA and DEAB treated embryos is presented in Table. 2.

\section{Discussion}

In the work described here we have investigated the role of the CYP26 enzymes in regulating RA signalling by treating zebrafish embryos with a Cyp26B1 antisense morpholino to determine the effect of knocking down translation of this gene during embryonic development. The developmental abnormalities observed were consistent with the patterns of expression of Cyp26B1 as there was an overall decrease in the size of the head region with smaller otic vesicles and microphthalmia. The hindbrain, otic vesicle and eye are domains of Cyp26B1 expression (Zhao et al., 2005).

The reduced head size of morpholino-treated embryos compared to wild-type prompted an analysis of hindbrain gene expression and brachiomotor neuron development. The expression of Hoxb1A, Hoxb3A and Krox-20 was not significantly altered at early stages apart from the clear observation of reduced rhombomere size. There was a suggestion that at later stages the integrity of $\mathrm{r} 4$ may break down because we saw an expansion of Krox-20expression into $\mathrm{r} 4$ in a minority of embryos. This requires a further detailed study.

Using the /slet-1-GFP transgenic zebrafish we showed a reduced number of BMNs in the trochlear, trigeminal and facial nuclei, but the greatest effect was on the vagal neurons which were highly disorganised and very reduced in number. Cyp26B1 is strongly expressed in the posterior hindbrain (Fig. 1B). Perhaps as a result of the reduced neuronal number the axonal projections from the trigeminal, facial and vagal neurons were less prolific and did not appear to extend into the pharyngeal arches which suggested an underlying deficit in pharyngeal arch development. Cyp26B1 is expressed in the branchial arches (Zhao et al., 2005).

Because of these possible branchial arch defects we examined $D / x 2$ expression, a gene which plays an essential role in the 
development of craniofacial cartilage as migrating neural crest cells express this gene (Bulfone et al., 1993; Akimenko et al., 1994). Injection of the Cyp26B1 morpholino resulted in a loss of $D / \times 2$ expression in the cranial neural crest cells. This led us to examine the jaw cartilage structure of morpholino treated embryos. This revealed that cartilaginous components of the neurocranium were missing or malformed in $34 \%$ of the morpholino injected embryos; components of the $1^{\text {st }}$ (mandibular) and $2^{\text {nd }}$ (hyoid) pharyngeal arches were absent or malformed in $50 \%$ of morpholino treated embryos; components of the posterior pharyngeal arches 3-7 (branchial - gill - arches 1-5) were missing or malformed in $96 \%$ of treated embryos.

We then determined whether this jaw phenotype resembled the effects of excess RA signalling or a deficiency by examining embryos treated with RA or DEAB, the latter being an inhibitor of RA synthesis. After DEAB treatment cartilaginous components of the neurocranium were missing or malformed in $18 \%$ of embryos; components of the $1^{\text {st }}$ (mandibular) and $2^{\text {nd }}$ (hyoid) pharyngeal arches were absent or abnormally formed in $59 \%$ of embryos; components populating the posterior pharyngeal arches 3-7 were missing or malformed in $96 \%$ of DEAB treated embryos. This is a very similar result to that obtained with the morpholino and, furthermore many of the detailed phenotypes of morpholino treatment were mimicked by DEAB. This type of defect where there is a greater prevalence in the more posterior branchial cartilages is seen in the $n / s$ mutant which has reduced RA signalling caused by a mutation in the Raldh2 gene (Begemann et al., 2001). On the other hand, excess RA treatment resulted in defective development of cartilage forming the neurocranium in $88 \%$ of embryos; components of the $1^{\text {st }}$ and $2^{\text {nd }}$ pharyngeal arches were malformed or missing in $83.5 \%$ of RA treated embryos and malformations of the posterior branchial gill arches were observed in $23 \%$ of RA treated embryos. Furthermore the most common phenotype we obtained with RA was a duplication of the second arch (certatohyals), the classical response to excess RA (Morriss Kay, 1993), acting via Hoxa1 (Zhang et al., 1994; Alexandre et al., 1996) and this was never seen after morpholino administration.

So it seemed that these jaw cartilage phenotypes resembled those associated with RA deficiency rather than RA excess and the same conclusion can be arrived at from the effects of the morpholino on BMN organisation. $10^{-8} \mathrm{M}$ RA, administered to Islet-1-GFP transgenic zebrafish embryos at late blastula stage resulted in a three-to fourfold increase in vagal BMNs neurons (Linville etal., 2004). In contrast the nls mutant which has reduced RA signalling due to a mutation in the Raldh2 gene has a vagal nucleus which is reduced by $90 \%$ compared to wild type (Begemann et al., 2004). Similarly, when embryos were treated with RA antagonists or $D E A B$ at the blastula stage the same vagal phenotype was observed. Reduced RA signalling on BMNs therefore also accords with the Cyp26B1 morpholino phenotype. The altered hindbrain structure in which there were no patterning abnormalities, only an overall reduction in size does not resemble the effects of excess RA either. Excess RA results in anterior rhombomere respecification or deletion of the presumptive cerebellar region in zebrafish embryos (Hill et al., 1995).

Recently, Hernandez and colleagues described the hindbrain phenotype resulting from loss of function of Cyp26a1, Cyp26b1 and Cyp26c1 in the developing zebrafish embryo (Hernandez et al., 2007). On administering their Cyp26b1 antisense morpholino they did not observe a phenotype. Their Cyp26b1 morpholino sequences were based on the ATG region and the exon-2-intron-2 DNA sequences of the Cyp26b1 gene. We extensively tested three separate morpholino sequences (which were all different from Hernandez and colleagues). Only one of these, the sequence based around the exon-1-intron-1 region of the gene resulted in a phenotype. This may explain why Hernandez et al., did not observe a similar phenotype as observed in this study.

As described in the Introduction there are several aspects of the zebrafish Cyp26A1 morpholino phenotype which also resemble a lack of RA signalling including loss of pectoral fins and failure of the common cardinal vein to form. Thus although there is solid evidence to support the idea that the CYP26s catabolise the RA signal in the mouse embryo the evidence for a similar role in the zebrafish embryo is by no means so clear cut as the knockdown phenotypes are not the same. It is already known that the products of the CYP26s are biologically active: 4-oxo$\mathrm{RA}$ respecifies anteroposterior pattern in the Xenopus embryo by activating RAR $\beta$ (Pijnappel et al., 1993; Nikawa et al., 1995), it can rescue cardiovascular defects in the vitamin A-deficient quail (Kostetskii et al., 1998) and restore sperm production in vitamin A-deficient mice (Gaemers et al., 1996). 4-oxo-RA, 4$\mathrm{OH}-\mathrm{RA}$ and 5,6-epoxy-RA can change epidermal thickness in mouse skin (Reynolds et al., 1993) and each of these compounds can rescue the vitamin A-deficient quail embryo (Reijntjes et al., 2005). Further experiments including rescue of morpholino treated zebrafish with the CYP26 products will provide valuable data on whether these enzymes have different roles in the mouse than in the zebrafish.

\section{Materials and Methods}

\section{Zebrafish stocks}

Fish lines were maintained at King's College London (KCL). Staging and husbandry was as described by Westerfield (Westerfield, 1995). The transgenic zebrafish embryos expressing green fluorescent protein under the control of the islet-1 promoter were kindly provided by $\mathrm{Dr}$ Corinne Houart.

\section{Morpholino synthesis}

The mouse CYP26B1 sequence (GenBank accession no. NM_175475) was used to search the zebrafish EST database (www.ensembl.org/Danio_rerio) and these ESTs were used to identify zebrafish contig ctg10569.1 (Sanger Centre assembly 7). The exon splice donor sequences were identified by the consensus sequences around 5' and 3' splice sites - (5')GU and (3')AG of the intron. The nucleotide sequence for exon 1 and the exon 1 splice donor sequence was sent to Gene Tools who identified and synthesized the following oligonucleotide:- CTTACTCGCGCTTAACCTGAAAGAAC. The morpholino was resuspended in sterile $\mathrm{H}_{2} \mathrm{O}$ to a concentration of $20 \mathrm{mg} / \mathrm{ml}$ and stored at $-70^{\circ} \mathrm{C}$.

\section{Embryo microinjection}

A morpholino concentration of $2.75 \mathrm{mg} / \mathrm{ml}$ was prepared. Approximately $2 \mathrm{nl}$ of morpholino was injected into the yolk of 1-8 cell-stage wild type and islet-1-GFP embryos using a pressurized microinjection device (Picosprizter II, General Value Corporation).

\section{Semiquantitative reverse transcription-PCR}

To determine whether the Cyp26B1-splice morpholino was blocking 
CYP26B1 and the cartilaginous cranial neural crest

splicing of the zebrafish Cyp26B1 primary RNA transcripts, semiquantitative reverse transcription-PCR was carried out.

\section{Primer design}

The forward primer was selected from exon 1 of $\operatorname{ctg} 20569.1$ as follows:-

5'-TGTCCATGGCACTTCTTCTG-3'. The reverse primer was selected from exon 2 of ctg20569. 1 as follows:- 5'-ACATTCTCTGCCCCAGTGAC3 '. These nucleotide sequences are complementary to +814 to +833 (forward) and +1060 to +1041 (reverse) of the Cyp26B1 mRNA (GenBank accession no. AY321366), generating a 246 bp product in wild type zebrafish embryos. Sequences were entered into NCBI BLAST to ensure no sequence homology with known genes.

RNA from 30 somite stage wild type and Cyp26B1 morpholino injected wild type embryos was extracted and measured using the same methods as previously described. For all semiquantitative RT-PCR reactions single-stranded cDNA was synthesised from $1 \mu \mathrm{g}$ of total cellular RNA. cDNA synthesis was by using M-MuLV reverse transcriptase (Amersham Pharmacia Biotech). The PCR reaction was carried out using $1 \mu \mathrm{l}$ of the retrotranscription reaction in a final volume of $50 \mu \mathrm{l}$, containing $10 \times \mathrm{PCR}$ buffer, $1.5 \mathrm{mmol} / \mathrm{L} \mathrm{MgCl}_{2}, 200 \mu \mathrm{M}$ each dNTPs, $0.2 \mu \mathrm{M}$ each primer and 1.25 units of Taq DNA polymerase (QIAGEN).

The zebrafish ALCAM gene which codes for a cell adhesion molecule (also known as neurogenin) was co-amplified in each experiment to indicate equal amounts of CDNA in the samples and the primers were a kind gift from Dr Chris Mann. Forward and reverse primers were used to generate a $1 \mathrm{~kb}$ product. PCR amplification conditions were: $94^{\circ} \mathrm{C}$ for 3 minutes followed by the cyclic program at $94^{\circ} \mathrm{C}$ for 30 seconds, $58^{\circ} \mathrm{C}$ for 30 seconds and $72^{\circ} \mathrm{C}$ for 1 minute for 32 cycles. For each primer set, an increasing linear number of PCR cycles were performed with otherwise fixed conditions to determine the optimal number of cycles to be used. The PCR products $(20 \mu \mathrm{l})$ were subjected to electrophoresis in $1 \%(\mathrm{w} / \mathrm{v})$ agarose gel, visualized by UV after ethidium bromide staining.

\section{Whole mount in situ hybridisation}

This was performed by standard procedures on dechorionated fixed embryos and involved treatment with Proteinase $\mathrm{K}$, refixing, prehybridisation and a hybridisation mix that contained approximately $1 \mu \mathrm{g} / \mathrm{ml}$ DIG labelled antisense RNA probe for Cyp26B1 and hybridisation was carried out overnight at $65^{\circ} \mathrm{C}$. The embryos were washed, blocked with $2 \%$ BBR in MABT for 1 hour and incubated overnight in $2 \%$ BBR, antiDIG diluted 1:2000 in MABT at $4^{\circ} \mathrm{C}$. The antibody was removed and the probe detected using BM Purple AP substrate, precipitating (Boehringer Mannheim) and the reaction stopped by washing in $20 \mathrm{mM}$ EDTA in PBST and then the embryos were fixed in $4 \%$ PFA.

\section{Victoria blue staining}

Embryos were fixed in $4 \%$ paraformaldehyde overnight, then placed into $50 \%$ ethanol for 15 mins followed by acid alcohol for $1 \mathrm{~h}$. They were then stained in 1\% Victoria blue (made up in acid alcohol) for $15 \mathrm{mins}$ and dehydrated in a graded series of alcohols $(70 \%, 90 \%, 95 \%, 100 \%, 100 \%)$. Finally, the embryos were cleared in methyl salicylate.

\section{Acknowledgements}

We would like to thank Carl Hobbs for preparing plastic sections, Corinne Houart for the Islet1-GFP zebrafish embryos and Vicky Prince for zebrafish Hox probes. We also thank the MRC for financial support for this project.

\section{References}

ABU-ABED S., DOLLE.P, METZGER D., BECKETT B., CHAMBON P. and PETKOVICH M. (2001). The retinoic acid-metabolizing enzyme, CYP26A1, is essential for normal hindbrain patterning, vertebral identity and development of posterior structures. Genes Dev. 15: 226-240.
AKIMENKO M.A., EKKER M., WEGNER J., LIN W. and WESTERFIELD M. (1994). Combinatorial expression of three zebrafish genes related to distal-less: part of a homeobox gene code for the head. J. Neurosci. 14: 3475-3486.

ALEXANDRE D., CLARKE J.D.W., OXTOBY E., YAN Y-L., JOWETT T. and HOLDER N. (1996). Ectopic expression of Hoxa-1 in the zebrafish alters the fate of the mandibular arch neural crest and phenocopies a retinoic acid-induced phenotype. Development 122: 735-746.

BEGEMANN G., SCHILLING T.F, RAUCH G.J., GEISLER R. and INGHAM P.W. (2001). The zebrafish neckless mutation reveals a requirement for raldh2 in mesodermal signals that pattern the hindbrain. Development 128: 3081-3094.

BEGEMANN G., MARX M., MEBUS K., MEYER A. and BASTMEYER M. (2004). Beyond the neckless phenotype: influence of reduced retinoic acid signaling on motor neuron development in the zebrafish hindbrain. Dev. Biol. 271: 119-129.

BULFONE A,. KIM H.J., PUELLES L., PORTEUS M.H., GRIPPO J.F. and RUBENSTEIN J.L. (1993). The mouse DIx-2 (Tes-1) gene is expressed in spatially restricted domains of the forebrain, face and limbs in midgestation mouse embryos. Mech. Dev. 40: 129-140.

DE ROOS K., SONNEVELD E., COMPAAN B., TEN BERGE D., DURSTON A.J. and VAN DER SAAG P.T. (1999). Expression of retinoic acid 4-hydroxylase (CYP26) during mouse and Xenopus laevis embryogenesis. Mech. Dev. 82: 205-211.

DERSCH H. and ZILE M.H. (1993). Induction of normal cardiovascular development in the vitamin A-deprived quail embryo by natural retinoids. Dev. Biol. 160: 424-433.

DUPE V. and LUMSDEN A. (2001). Hindbrain patterning involves graded responses to retinoic acid signalling. Development 128: 2199-2208.

ELLIES D.L., LANGILLE R.M., MARTIN C.C., AKIMENKO M.A. and EKKER M. (1997). Specific craniofacial cartilage dysmorphogenesis coincides with a loss of dlx gene expression in retinoic acid-treated zebrafish embryos. Mech. Dev. 61: 23-36.

EMOTO Y., WADA H., OKAMOTO H., KUDO A. and IMAI Y. (2005). Retinoic acidmetabolizing enzyme Cyp26a1 is essential for determining territories of hindbrain and spinal cord in zebrafish. Dev. Biol. 278: 415-427.

FREEMAN M.(2000). Feedback control of intercellular signalling in development. Nature 408: 313-319.

FUJII H., SATO T., KANEKO S., GOTOH O., FUJII-KURIYAMA Y., OSAWA K., KATO S. and HAMADA H. (1997). Metabolic inactivation of retinoic acid by a novel P450 differentially expressed in developing mouse embryos. EMBO 16 : 4163-4173.

GAEMERS I.C., VAN PELT A.M.M., VAN DER SAAG P.T. and, DE ROOIJ D.G. (1996). All-trans-4-oxo-retinoic acid: a potent inducer of in vivo proliferation of growth-arrested A spermatogonia in the vitamin A-deficient mouse testis. Endocrinology 137: 479-486.

GRAHAM A. (2002). Jaw development: chinless wonders. Curr. Biol. 12: R810R812.

GRANDEL H., LUN K., RAUCH G-J., RHINN M., PIOTROWSKI T., HOUART C., SORDINOP., KUCHLER A.M., SCHULTE-MERKER S., GEISLER R., HOLDER N., WILSON S.W. and BRAND, M. (2002). Retinoic acid signalling in the zebrafish embryo is necessary during pre-segmentation stages to pattern the anterior-posterior axis of the CNS and to induce a pectoral fin bud. Development 129: 2851-2865.

GU X., XU F., WANG X., GAO X. and ZHAO Q. (2005). Molecular cloning and expression of a novel CYP26 gene (cyp26d1) during zebrafish early development. Gene Expr. Patt. 5: 733-739.

HERNANDEZ R.E., PUTZKE A.P., MYERS J.P., MARGARETHA L. and MOENS C.B. (2007). Cyp26 enzymes generate the retinoic acid response pattern necessary for hindbrain development. Development 134: 177-187.

HIGASHIJIMA S., HOTTA Y. and OKAMOTO H. (2000). Visualization of cranial motor neurons in live transgenic zebrafish expressing green fluorescent protein under the control of the islet-1 promoter/enhancer. J. Neurosci. 20: 206-218.

HILL J., CLARKE J.D., VARGESSON N., JOWETT T. and HOLDER N. (1995). Exogenous retinoic acid causes specific alterations in the development of the midbrain and hindbrain of the zebrafish embryo including positional respecification of the Mauthner neuron. Mech. Dev. 50: 3-16.

HOLLEMANN T., CHEN Y., GRUNZ H. and PIELER T. (1998). Regionalized metabolic activity establishes boundaries of retinoic acid signalling. EMBO J. 
17: 7361-7372

KASTNER P., CHAMBON P. and LEID M. 1(994). Role of Nuclear retinoic acid recepotors in the regulation of gene expression. In Vitamin $A$ in Health and Disease. pp.189-238. Marcel Dekker, New York.

KESSEL M. and GRUSS P. (1991). Homeotic transformations of murine vertebrae and concomitant alteration of Hox codes induced by retinoic acid. Ce//67: 89104.

KLIEWER S.A., UMESONO K., EVANS R.M. and MANGELSDORF D. (1994). The retinoid $X$ receptors: modulators of multiple hormonal signalling pathways. In Vitamin A in Health and Disease. pp. 239-256. Marcel Dekker, New York.

KOCHHAR D.M. (1973). Limb development in mouse embryos. Analysis of teratogenic effects of retinoic acid. Teratology 7: 289-298.

KOSTETSKII I., YUAN S-Y., KOSTETSKAIA E., LINASK K.K., BLANCHET S., SELEIRO E., MICHAILLE J-J,. BRICKELL P. and ZILE M. (1998). Initial retinoid requirement for early avian development coincides with retinoid receptor coexpression in the precardiac fields and induction of normal cardiovascular development. Dev. Dynam. 213: 188-198.

LINVILLE A., GUMUSANELI E., CHANDRARATNA R.A. and SCHILLING T.F. (2004). Independent roles for retinoic acid in segmentation and neuronal differentiation in the zebrafish hindbrain. Dev. Biol. 270: 186-199.

MACLEAN G., ABU-ABED S., DOLLE P., TAHAYATO A., CHAMBON P. and PETKOVICH M. (2001). Cloning of a novel retinoic-acid metabolizing cytochrome P450, Cyp26B1 and comparative expression analysis with Cyp26A1 during early murine development. Mech. Dev. 107: 195-201.

MADEN M. 2002. Retinoid signalling in the development of the central nervous system. Nature Neurosci. 3: 843-853.

MARSHALL H., NONCHEV S., SHAM M.H., MUCHAMORE I., LUMSDEN A. and KRUMLAUF R. (1992). Retinoic acid alters hindbrain Hox code and induces transformation of rhombomeres 2/3 into a 4/5 identity. Nature 360: 737-741.

MCCAFFERY P., WAGNER E., O'NEIL J.O., PETKOVICH M. and DRAGER U.C. (1999). Dorsal and ventral territories defined by retinoic acid synthesis, breakdown and nuclear receptor expression. Mech. Dev. 82: 1190130.

MERCADER N., LEONARDO E., PIEDRA M.E., MARTINEZ A.C., ROS M.A. and TORRES M. (2000). Opposing RA and FGF signals control proximodistal vertebrate limb development through regulation of Meis genes. Development 127: 3861-3970.

MORRISS-KAY G. (1993). Retinoic acid and craniofacial development: molecules and morphogenesis. BioEssays 15: 9-15.

NIEDERREITHER K., ABU-ABED S., SCHUBAUR B., PETKOVICH M., CHAMBON $P$. and DOLLE P. (2002). Genetic evidence that oxidative derivatives of retinoic acid are not involved in retinoid signalling during mouse development. Nature Genet. 31: 84-88.

NIKAWA T., SCHULZ W.A., VAN DEN BRINK C.E., HANUSCH M., VAN DER S.P., STAHL W. and SIESH. (1995). Efficacy of all-trans-beta-carotene, canthaxanthin and all-trans-, 9-cis- and 4-oxoretinoic acids in inducing differentiation of an F9 embryonal carcinoma RAR beta-lacZ reporter cell line. Arch. Biochem Biophys. 316: 665-672.

PIJNAPPEL W.W.M., HENDRICKS H.F.J., FOLKERS G.E., VAN DENBRINK C.E., DEKKER E.J., EDELENBOSCH C., VAN DER SAAG P.T. and DURSTON A.J. (1993). The retinoid ligand 4-oxo-retinoic acid is a highly active modulator of positional specification. Nature 366: 340-344.

REIJNTJES S., GALE E. and MADEN M. (2003). Expression of the retinoic acid catabolising enzyme CYP26B1 in the chick embryo and its regulation by retinoic acid. Gene Expr. Patt. 3: 621-627.
REIJNTJES S., GALE E and MADEN M. (2004). Generating gradients of retinoic acid in the chick embryo: Cyp26C1 expression and a comparative analysis of the Cyp26 enzymes. Dev. Dynam. 230: 509-517.

REIJNTJES S., BLENTIC A., GALE E. and MADEN M. (2005). The control of morphogen signalling: Regulation of the synthesis and catabolism of retinoic acid in the developing embryo. Dev. Biol. 285: 224-237.

REYNOLDS N.J., FISHER G.J., GRIFFITHS C.E., TAVAKKOL A., TALWAR H.S., ROWSE P.E., HAMILTON T.A. and VOORHEES J.J. (1993). Retinoic acid metabolites exhibit biological activity in human keratinocytes, mouse melanoma cells and hairless mouse skin in vivo. J. Pharmacol. Exp. Ther. 266: 1636-1642.

SAKAI Y., MENO C., FUJII H., NISHINO J., SHIRATORI H., SAIJOH Y., ROSSANT J. and HAMADA H. (2001). The retinoic acid-inactivating enzyme CYP26 is essential for establishing an uneven distribution of retinoic acid along the anterio-posterior axis within the mouse embryo. Genes Dev. 15: 213-225.

SIRBU I.O., GRESH L., BARRA J. and DUESTER G. (2005). Shifting boundaries of retinoic acid activity control hindbrain segmental gene expression. Development 132: 2611-2622

SWINDELL E.C., THALLER C., SOCKANATHAN S., PETKOVICH M., JESSELL T.M. and EICHELE G. (1999). Complementary domains of retinoic acid production and degradation in the early chick embryo. Dev. Biol. 216: 282-296.

TAHAYATO A., DOLLE P. and PETKOVICH M. (2003). Cyp26C1 encodes a novel retinoic acid-metabolizing enzyme expressed in the hindbrain, inner ear, first branchial arch and tooth buds during murine development. Gene Exp. Patt. 3: 449-454.

VANDERSEA M.W., FLEMING P., MCCARTHY R.A. and SMITH D.G. (1998). Fin duplications and deletions induced by disruption of retinoic acid signaling. Dev. Genes Evol. 208: 61-68

WESTERFIELD M. (1995). The zebrafish Book. Guide for the Laboratory Use of Zebrafish (Danio rerio). Univ of Orgeon Press, Eugene.

WHITE J.A., BECKETT-JONES B., GUO Y.D., DILWORTH F.J., BONASORO J., JONES G. and PETKOVICH M. (1997). cDNA cloning of human retinoic acidmetabolizing enzyme (hP450RAl) identifies a novel family of cytochromes P450. J. Biol. Chem. 272: 18538-18541.

WHITE J.A., RAMSHAW H., TAIMI M., STANGLE W., ZHANG A, EVERINGHAM S., CREIGHTON S., TAM S.P., JONES G. and PETKOVICH M. (2000). Identification of the human cytochrome P450, P450RAI-2, which is predominantly expressed in the adult cerebellum and is responsible for all-trans-retinoic acid metabolism. Proc. Natl. Acad. Sci. USA 97: 6403-6408.

YASHIRO K., ZHAO X., UEHARA M., YAMASHITA K., NISHIJIMA M., NISHINO J. SAIJOH Y., SAKAI Y. and HAMADA H. (2004). Regulation of retinoic acid distribution is required for proximodistal patterning and outgrowth of the developing mouse limb. Develop. Cel/6: 411-422.

ZHAO Q., DOBBS-MCAULIFFE B. and LINNEY E. (2005). Expression of cyp26b1 during zebrafish early development. Gene. Expr. Patt. 5: 363-369.

ZHANG M., KIM H-J., MARSHALL H., GENDRON-MAGUIRE M., LUCAS D.A., BARON A., GUDAS L.J., GRIDLEY.T, KRUMLAUF R and GRIPPO JF. (1994). Ectopic Hoxa-1 induces rhombomere transformation in mouse hindbrain. Development 120: 2431-2442.

Received: 7th December 2006 Reviewed by Referees: 16th March 2007 Modified by Authors and Accepted for Publication: 8th May 2007 Published Online: 25th June 2007 
Related, previously published Int. J. Dev. Biol. articles

See our recent Special Issue on Developmental Biology in Britain edited by Jim Smith at:

http://www.ijdb.ehu.es/web/contents.php?vol=44\&issue $=1$

Retinoic acid is required for specification of the ventral eye field and for Rathke's pouch in the avian embryo Malcolm Maden, Aida Blentic, Susan Reijntjes, Sophie Seguin, Emily Gale and Anthony Graham

Int. J. Dev. Biol. (2007) 51: 191-200

Expression and regulation of Xenopus CRMP-4 in the developing nervous system Jacob Souopgui, Tiemo J. Klisch, Tomas Pieler and Kristine A. Henningfeld Int. J. Dev. Biol. (2007) 51: 2235-2235

A change in response to Bmp signalling precedes ectodermal fate choice

Chris T. Dee, Abigail Gibson, Andrea Rengifo, Shun-Kuo Sun, Roger K. Patient and Paul J. Scotting

Int. J. Dev. Biol. (2007) 51: 79-84

Fate of cranial neural crest cells during craniofacial development in endothelin-A receptor-deficient mice Makoto Abe, Louis-Bruno Ruest and David E. Clouthier

Int. J. Dev. Biol. (2007) 51: 97-105

TBX1, a DiGeorge syndrome candidate gene, is inhibited by retinoic acid

Lifeng Zhang, Tao Zhong, Yuexiang Wang, Qiu Jiang, Houyan Song and Yonghao Gui

Int. J. Dev. Biol. (2006) 50: 55-61

Retinoic acid repatterns axolotl lateral line receptors.

Melissa A Gibbs and R Glenn Northcutt

Int. J. Dev. Biol. (2004) 48: 63-66

Exogenous retinoic acid induces a stage-specific, transient and progressive extension of Sonic hedgehog expression across the pectoral fin bud of zebrafish.

Lisa Hoffman, Jennifer Miles, Fabien Avaron, Lynda Laforest and Marie-Andrée Akimenko

Int. J. Dev. Biol. (2002) 46: 949-956

Retinoic acid and limb regeneration-a personal view.

Malcolm Maden

Int. J. Dev. Biol. (2002) 46: 883-886

Retinoic acid response element in HOXA-7 regulatory region affects the rate, not the formation of anterior boundary expression.

Myoung H Kim, Jae S Shin, Sungdo Park, Man-Wook Hur, Mi-Ok Lee, Hyoungwoo Park and Chul-Sang Lee Int. J. Dev. Biol. (2002) 46: 325-328

Disto-proximal regional determination and intercalary regeneration in planarians, revealed by retinoic acid induced disruption of regeneration.

R Romero and D Bueno

Int. J. Dev. Biol. (2001) 45: 669-673

Stage-dependent responses of the developing lung to retinoic acid signaling.

R Mollard, N B Ghyselinck, O Wendling, P Chambon and M Mark

Int. J. Dev. Biol. (2000) 44: 457-462

Abnormalities of somite development in the absence of retinoic acid.

M Maden, A Graham, M Zile and E Gale

Int. J. Dev. Biol. (2000) 44: 151-159 


\section{IJDB Special Issue on}

\section{THE NOGENT INSTITUTE}

Institut d'Embryologie Cellulaire et Moleculaire Nogent-sur-Marne

\section{Edited by Fran çoise Dieterlen}

Forward

by Nicole M. Le Douarin

Preface

by Françoise Dieterlen

\section{INTRODUCTORY PAPERS}

L'École de Nogent: the contributions of Etienne Wolff and Nicole Le Douarin

by Charles Galperin

The Nogent Institute - 50 Years of Embryology by Nicole M. Le Douarin

\section{CONTRIBUTIONS}

Early stages of neural crest ontogeny: formation and regulation of cell delamination

by Chaya Kalcheim and Tal Burstyn-Cohen

Brain switching: studying evolutionary behavioral changes in the context of individual brain development

by Evan Balaban

Commitment of hematopoietic stem cells in avian and mammalian embryos: an ongoing story by Françoise Dieterlen-Lièvre

The Le Douarin phenomenon: a shift in the paradigm of developmental self-tolerance by António Coutinho

Regulatory $\mathrm{T}$ cells in the establishment and maintenance of self-tolerance: role of the thymic epithelium

by Josselyne Salaün, Catherine Corbel and Nicole M. Le Douarin

Migration of neural crest-derived enteric nervous system precursor cells to and within the gastrointestinal tract

by Alan J. Burns

The instability of the neural crest phenotypes: Schwann cells can differentiate into myofibroblasts

by Carla Real, Corinne Glavieux-Pardanaud, Pierre Vaigot, Nicole Le Douarin and Elisabeth Dupin

Neural crest derivatives in ocular and periocular structures

by Sophie Creuzet, Christine Vincent and Gérard Couly

Endothelin receptor $B$ is required for the expansion of melanocyte precursors and malignant melanoma

by Ronit Lahav
Cellular dynamics and molecular control of the development of organizer-derived cells in quailchick chimeras

by Jean-Baptiste Charrier, Martin Catala, Françoise Lapointe, Nicole Le Douarin and Marie-Aimée Teillet

Experimental study of early olfactory neuron differentiation and nerve formation using quailchick chimeras

by Fabrice L. Lalloué and Christiane S. Ayer-Le Lièvre

Single-cell transcriptional profiles and spatial patterning of the mammalian

olfactory epithelium

by lan Tietjen, Jason Rihel and Catherine G. Dulac

Oligodendrocyte development in the embryonic brain: the contribution of the plp lineage

by Barbara Le Bras, Elli Chatzopoulou, Katharina

Heydon, Salvador Martínez, Katzuhiko Ikenaka Laetitia Prestoz, Nathalie Spassky, Bernard Zalc and Jean-Léon Thomas

Common mechanisms for boundary formation in somitogenesis and brain development: shaping the 'chic' chick

by Yoshiko Takahash

Isthmus organizer and regionalization of the mesencephalon and metencephalon

by Harukazu Nakamura and Yuji Watanabe

Transfer of an avian genetic reflex epilepsy by embryonic brain graft: a tissue autonomous process?

by Marie-Aimée Teillet, Robert Naquet and Cesira Batini

Embryonic development of the human hematopoietic system

by Manuela Tavian and Bruno Péault

Of birds and mice: hematopoietic stem cell development

by Isabelle Godin and Ana Cumano

Vascular development: from precursor cells to branched arterial and venous networks by Anne Eichmann, Li Yuan, Delphine Moyon,

Ferdinand Lenoble, Luc Pardanaud and Christiane Bréant

Tracing the hemangioblast during embryogenesis: developmental relationships between endothelial and hematopoietic cells by Thierry Jaffredo, Karine Bollerot, Daisuke Sugiyama, Rodolphe Gautier and Cécile Drevon $\alpha$ llb integrin, a novel marker for hemopoietic progenitor cells

by Catherine Corbel, Pierre Vaigot and Josselyne Salaün

The human $\mathrm{T}$ cell immune response to EpsteinBarr virus

by Elise Landais, Xavier Saulquin and Elisabeth Houssaint

Development and function of bombesin-like peptides and their receptors

by Hiroko Ohki-Hamazaki, Maiko Iwabuchi and Fumihiko Maekawa

Sclerotome development and morphogenesis: when experimental embryology meets genetics by Anne-Hélène Monsoro-Burq

Synchronised cycling gene oscillations in presomitic mesoderm cells require cell-cell contact

by Miguel Maroto, J. Kim Dale, Mary-Lee Dequéant, Anne-Cécile Petit and Olivier Pourquié

Running after the clock

by Catarina Freitas, Sofia Rodrigues, Leonor Saúde and Isabel Palmeirim

Three developmental compartments involved in rib formation

by Hirohiko Aoyama, Yoko Mizutani-koseki and Haruhiko Koseki

Antero-posterior patterning of the vertebrate digestive tract: $\mathbf{4 0}$ years after

Nicole Le Douarin's PhD thesis by Anne Grapin-Botton

(4)

Mouse-chick neural chimeras

by Josiane Fontaine-Pérus and Yvonnick Chéraud

Vasculogenesis and angiogenesis in the mouse embryo studied using quail/mouse chimeras by Michel Pudliszewski and Luc Pardanaud

The cap ' $n$ ' collar family member NF-E2-related factor 3 (Nrf3) is expressed

in mesodermal derivatives of the avian embryo by Heather $\mathrm{C}$. Etchevers

Notch in vertebrates - molecular aspects of the signal

by Ken-Ichi Katsube and Kei Sakamoto

\section{ORDER BY}

Web: http://www.intjdevbiol.com

E-mail: ijdb@ehu.es

FAX: +34-94-601-3266

POST: to the address shown to the right

The International Journal of Developmental Biology 